\title{
Ethical statement in medical research manuscripts: A Necessary step for
}

\section{quality control}

\author{
Sathian B ${ }^{1}$, Banerjee $\mathbf{I}^{2}$, Sreedharan J3, Roy B ${ }^{4}$, Yadav R J5
}

${ }^{1}$ Assistant Professor, Department of Community Medicine, Manipal College of Medical Sciences, Pokhara, Nepal

${ }^{2}$ Assistant Professor, Department of Pharmacology , Manipal College of Medical Sciences, Pokhara, Nepal

${ }^{3}$ Assistant Director, Research Division, Gulf Medical University, Ajman, UAE

${ }^{4}$ Assistant Professor, Department of Physiology , Manipal College of Medical Sciences, Pokhara, Nepal

${ }^{5}$ Director Grade Scientist, Indian Council of Medical Research, Ansari Nagar, Delhi, India

\section{Chief Editor}

Dr. Padam Simkhada

Technical Editor

Dr. Nishida Chandrasekharan

Formatting Editor

Dr. Ram Lakhan

\section{Editorial}

\section{Corresponding Author}

Dr. Brijesh Sathian PhD

Assistant Professor

Department of Community Medicine,

MCOMS, Pokhara, Nepal

E-mail: drsathian gmail.com

\section{Abstract}

Recently there are several budding medical journals which are coming from developing countries and also there is a large number of publishers. It will foster medical research from these countries. Authors will improve the skill of medical writing because of these journals senior, experienced international/ national editorial and review board. Also this team is responsible for the quality of the journal. Journals primary aim should not be making money and get other benefit to the people who are dealing with it. Journals should produce evidence based new information to

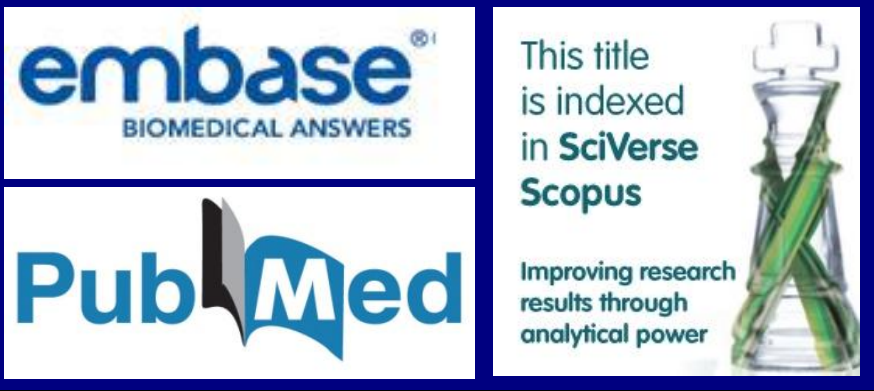

the medical science which will benefit to the new generation physicians, scientists and readers.

There is a tremendous increase in the medical research articles in the recent years because most of the institutions, universities and funding agencies consider the publication history of the scientists for their promotion and incentive. It results with good practice and bad practice of research. There are several scientists and teaching faculty members who publish the articles without proper data or they plagiarise other scientist work. It can be stopped only by the national medical research authorities like Indian Council of Medical Research [India], Nepal Health Research Council [Nepal], etc. for each country level and the Institutional Research and Ethics Committee in the institutional level.

Keywords: Ethics, Medical Research, Nepal, Declaration of Helsinki

\section{Background}

Recently there are several budding medical journals which are coming from developing countries and also there is a large number of publishers. It will foster medical research 


\section{Ethical statement in medical research}

from these countries. Authors will improve the skill of medical writing because of these journals senior, experienced international/ national editorial and review board. Also this team is responsible for the quality of the journal. Journals primary aim should not be making money and get other benefit to the people who are dealing with it. Journals should produce evidence based new information to the medical science which will benefit to the new generation physicians, scientists and readers ${ }^{1}$.

There is a tremendous increase in the medical research articles in the recent years because most of the institutions, universities and funding agencies consider the publication history of the scientists for their promotion and incentive. It results with good practice and bad practice of research. There are several scientists and teaching faculty members who publish the articles without proper data or they plagiarise other scientist work ${ }^{2}$. It can be stopped only by the national medical research authorities like Indian Council of Medical Research [India], Nepal Health Research Council [Nepal], etc. for each country level and the Institutional Research and Ethics Committee in the institutional level.

When coming to the journal level then Chief Editor is responsible for the ethics in a manuscript published in a journal and it is his duty to reject the fraudulent research paper submitted to the journal. So whenever a manuscript submitted to the journal first step is to find out whether the ethical statement in the manuscript is well written and the ethical approval letter is genuine. If these criteria are not fulfilled then the journals like Nepal Journal of Epidemiology will reject the manuscript in the preliminary editorial review round.

\section{Components which should be mandatory in a good} medical research Manuscript

1. Ethics approval should be obtained prior to the commencement of the study from the Institutional Research and Ethics Committee which is approved by the national medical research authority [Indian Council of Medical Research, Nepal Health Research Council etc or Institutional Research Council] and the scanned copy send to the journal managing editor and clearance number should be written in the manuscript.

2. Written/ verbal consent should be taken from the patients while acquiring the data and it should be mentioned in the manuscript if it is a clinical study.

3. Informed consent should be taken from the parents or guardians on the behalf of participants aged less than 18 years.

4. The research should be conducted in accordance to the Declaration of Helsinki.

5. Researcher should cite the latest Declaration of Helsinki for ethical statement in the manuscript.

Importance of Citing the latest Declaration of Helsinki for ethical statement in medical research manuscripts ${ }^{3-10}$

The World Medical Association has developed the Declaration of Helsinki as a statement of ethical principles to provide guidance to physicians and other participants in medical research involving human subjects. Medical research involving human subjects includes research on identifiable human material or identifiable data. It is the duty of the physician to promote and safeguard the health of their patients. Knowledge and awareness of the physician are dedicated to the fulfilment of this duty. The Declaration of Geneva of the World Medical Association binds the physician with the words, "The health of my patient will be my first consideration." The International Code of Medical Ethics declares that, "The physician shall act only in the patient's interest to foster care physicians who may be able to weaken the mental and physical fitness of patient"11. All provisions of the Declaration of Helsinki should be followed, especially the need for appropriate ethical and scientific review. Because of these reasons the researcher should cite the Declaration of helsinki in medical research manuscripts.

\section{Conflict of interest:}

None

\section{References:}

1. Sathian B. Methodological Rigors in Medical Journals from Developing Countries: An Appraisal of the Scenario in Asia . Nepal Journal of Epidemiology 2011;1 (5):141-43. http://dx.doi.org/10.3126/nje.v1i5.6151

2. Banerjee I, Roy B, Sathian B, Banerjee I, Saha A. Plagiarism: Who is responsible author or the journal editors? Nepal Journal of Epidemiology 2013;3 (3): 277 278.

http://dx.doi.org/10.3126/nje.v3i3.9190

3.Banerjee I, Banerjee I, Roy B, Sathian B, Khadkha S, Chakraborty PK, Saha A, Pugazhandhi B. Impact of ethnicity, unemployment and economy on mental disorders : A study from Western Nepal. Nepal Journal of Epidemiology 2014, 4(1):306-15. http://dx.doi.org/10.3126/nje.v4i1.10132

4. Banerjee I, Roy B, Sathian B, Banerjee I, Kumar SS, Saha A: Medications for Anxiety: A Drug utilization study in Psychiatry Inpatients from a Tertiary Care Centre of Western Nepal. Nepal Journal of Epidemiology 2010, 1(4):119-25.

http://dx.doi.org/10.3126/nje.v1i4.5753

5. Banerjee I, Sathian B, Chakraborty PK, Banerjee I, Roy B, Jauhari AC, Saha A. Pharmacotherapy of Bipolar Affective Disorder: A Hospital Based Study from Sub Himalayan Valley of Nepal. J Clin Diagn Res. 2014, Jun. 8(6): HC22$\mathrm{HC} 27$.

DOI: $10.7860 / J C D R / 2014 / 8661.4524$

6. Banerjee I, Roy B, Sathian B, Banerjee I, Chakraborty PK, Saha A. Socio demographic profile and utilization pattern of antipsychotic drugs among schizophrenic inpatients: a cross sectional study from western region of Nepal. BMC Psychiatry. $2013 \quad$ Mar 22;13:96. http://dx.doi.org/10.1186/1471-244X-13-96 PMid:23522357

7. Banerjee I, Roy B, Banerjee I, Sathian B, Mondol M, Saha A: Depression and its Cure: A Drug Utilization Study from a 
Tertiary Care Centre of Western Nepal. Nepal Journal of Epidemiology 2011, 1(5):144-52. http://dx.doi.org/10.3126/nje.v1i5.6152

8. Banerjee I, Roy B, Sathian B, Banerjee I, Pugazhandhi B, Jauhari AC, Saha A, Chakraborty PK. Treatment and the impact of Age, Gender and occupation on Neurotic, stressrelated and Somatoform disorders: A study from Nepal. Neurons. 2014, 1(1): 10-15

9. Banerjee I, Banerjee I, Das K N, Sathian B, Pugazhandhi B, Roy B, Banerjee S M, Khadka S. Etiological Factors of Non Alcohol Non Gallstone Related Acute Pancreatitis: A Cross sectional hospital based study from Medical College and Hospital, Kolkata, West Bengal. Nepal. Nepal Journal of Epidemiology 2014, 4(3): 351-62.

http://dx.doi.org/10.3126/nje.v4i3.10663

10. Banerjee I, Saha A, Banerjee I, Chakraborty PK, Jauhari A C, Sathian B, Roy B, Pugazhandhi B, Khadka S. Psychiatric illnesses among Dalit Nepalese population. Nepal Journal of Epidemiology 2014, 4(3): 370-77.

http://dx.doi.org/10.3126/nje.v4i3.10667

11. WMA Declaration of Helsinki - Ethical Principles for Medical Research Involving Human Subjects. 64th WMA General Assembly, Fortaleza, Brazil, October 2013.

[online]2014 [cited 2014 June 15]. Available from: URL: http://www.wma.net/en/30publications/10policies/b3/

Article Information

\section{Article history}

\begin{tabular}{|l|c|}
\hline Received & $2^{\text {nd }}$ June 2014 \\
\hline Received in revised form & $15^{\text {th }}$ June 2014 \\
\hline Accepted & $28^{\text {th }}$ June 2014 \\
\hline
\end{tabular}

